\title{
Two decades' contribution of occupational medicine training in Thailand: experience from the foundation with a view toward the future
}

\author{
Jate Ratanachina', Pornchai Sithisarankul ${ }^{2 *}$
}

\begin{abstract}
For 2 decades, the Department of Preventive and Social Medicine, Faculty of Medicine, Chulalongkorn University, has served the Occupational Medicine Residency training program in Thailand. Graduates of this program undertake to work in occupational medicine to promote health and prevent morbidity and mortality in the workplace and provide occupational medical services for the working population in Thailand. Qualifying for a Postgraduate Diploma in Occupational Medicine in Thailand can be achieved in 2 ways: through a 3-year residency training or 5 years of working experience in the field of occupational medicine combined with an elective 2-month short course. There are currently 159 Thai board-certified occupational medicine physicians. Occupational medicine physicians in Thailand work in both public and private healthcare facilities. A number of certified occupational physicians occupy leading national health positions in various government and academic organizations. Knowledge of occupational medicine is currently essential for undergraduate medical students as specified in the medical competency assessment criteria of the Thai Medical Council. Updating content and incorporating needs of employers are keys to success for Thailand, as a country with an occupational medicine training program in its initial stages. In Thailand, the supply of occupational medicine physicians is still less than the increasing demand. Advancement of health research schemes would contribute to the curriculum. Occupational medicine development in Thailand needs to address challenges in local issues including work in the informal sector, particularly in agriculture, and incorporate standardization and international consistency into the training curriculum and qualifying management.
\end{abstract}

Keywords: occupational medicine, Thailand, training

For 2 decades, the Department of Preventive and Social Medicine, Faculty of Medicine, Chulalongkorn University, has served the Occupational Medicine Residency training program in Thailand [1]. Graduates of this program undertake to work in the field of occupational medicine to promote health and prevent morbidity and mortality in workplaces and provide occupational medical services for the working population in Thailand. In Thailand, occupational medicine is a specialty for Thai physicians. However, occupational medicine and its training program still need to be expanded to increase

*Correspondence to: Pornchai Sithisarankul, Department of Preventive and Social Medicine, Faculty of Medicine, Chulalongkorn University, Bangkok 10330, Thailand, e-mail: pornchai.si@chula.ac.th

'Department of Preventive and Social Medicine, King Chulalongkorn Memorial Hospital, Bangkok 10330, Thailand

${ }^{2}$ Department of Preventive and Social Medicine, Faculty of Medicine, Chulalongkorn University, Bangkok 10330, Thailand 
its understanding by and relevance to society. The purposes of the present article are to describe the development of occupational medicine training and to opine possible occupational medicine trends in Thailand.

\section{Foundation of occupational medicine training}

\section{Occupational medicine in Thailand history}

Like other countries, Thai occupational medicine, a branch of preventive medicine relied on for health and well-being of the working population in Thailand, presently being $>37.4$ million [2], has evolved from industrial medicine. Initially, Thai industrial medicine physicians mostly graduated from Europe and Singapore. Later, these physicians worked separately in public practice, mostly in universities. This group of industrial medicine physicians together preliminarily comprised the Occupational Medicine Club.

On August 19, 1997, a number of occupational medicine physicians comprising those from universities and the Thai Ministry of Public Health initiated the Occupational Medicine Society of Thailand, which aimed to support occupational medicine collaborations and movements in Thailand, specifically academic activities such as annual meetings, occupational medicine short course training, and field trips abroad. Ultimately, the society was registered as the Association of Occupational and Environmental Diseases of Thailand in 2003 [3].

\section{Occupational medicine training}

In 1992, with the help of Department of Medical Services, Thai Ministry of Public Health, the occupational medicine physicians initiated a 2-month short course training in occupational medicine. During 1992-1996, they also succeeded in drafting the 3-year occupational medicine residency training program and getting it approved by the Medical Council of Thailand.

Occupational medicine became the fifth branch of the preventive medicine training program in 1996; the first 4 branches were clinical preventive medicine, public health, aviation medicine, and epidemiology, respectively. Consequently, in 1998, the Department of Preventive and Social Medicine, Faculty of Medicine, Chulalongkorn University, became the first institute to provide occupational medicine residency training. Three physicians were enrolled to the course as first-year residents in 1998 [4].

\section{Current occupational medicine training program}

There are currently 159 Thai occupational medicine physicians. These physicians were awarded the Postgraduate Diploma in Occupational Medicine in Thailand, and their qualification was achieved through 2 ways: by attending a 3 -year residency training or by 5 years of working experience in the field of occupational medicine combined with an elective 2-month short course. This 2-month short course evolved from the original short course and is now the responsibility of Nopparat Rajathanee Hospital. Knowledge of occupational medicine is currently essential for Thai undergraduate medical students as specified in the medical competency assessment criteria of the Thai Medical Council.

\section{Certification in occupational medicine}

To be certified as an occupational medicine physician in Thailand, there are 2 ways of qualifying the Preventive Medicine (Occupational Medicine Branch) Board-certified examination for the Diploma in Occupational Medicine held by the Medical Council of Thailand.

First, being trained in the 3-year occupational medicine residency program will provide Graduate Diploma in Clinical Sciences Program in Occupational Medicine. The first year of the training comprises a 2-month short course in occupational medicine, environmental medicine rotation, occupational medicine-related clinical rotations including internal medicine (in turn, including toxicology, dermatology, neurology, respirology, and cardiology), orthopedics, ophthalmology, otorhinolaryngology, psychiatry, rehabilitation, gynecology, and occupational medicine clinics. The second year of the training is a Master of Science study comprising course work and a thesis examination. The third and final year of the training is a practical year; an occupational medicine resident is assigned to participate in walk-through surveys, occupational medicine clinics, practicing in occupational medicine at large enterprises, tertiary and occupational medicine-specialized hospitals, and the Bureau of Occupational and Environmental Diseases of the Ministry of Public Health. The residents may be able to obtain financial support from the Workmen Compensation Fund, Social Security Office, and the Ministry of Labor in Thailand.

The Department of Preventive and Social Medicine, Faculty of Medicine, Chulalongkorn University, first organized the training in Thailand in 1998 [5]. Until now, 63 occupational medicine residents have registered in the program offered by Chulalongkorn University, followed by 4 other institutions, including the Occupational and Environmental 
Medicine Center of Nopparat Rajathanee Hospital (2006), the Faculty of Medicine, Khon Kaen University (2011), Phramongkutklao Hospital (2013), and the Faculty of Medicine, Prince of Songkla University (2014).

As the number of occupational medicine physicians in Thailand is not sufficient to meet the needs of the country, a second category of certification for occupational medicine physicians in Thailand is through practicing occupational medicine services or teaching in related fields of occupational medicine for at least 5 years continuously combined with the elective 2-month short course in occupational medicine. Before becoming eligible for the board-certified examination in this category, the physician has to publish 2 research articles. The short course was initially organized by the Thai Bureau of Medical Technical Development, Department of Medical Services, Ministry of Public Health, in 1992. Since 2003, the Occupational and Environmental Medicine Center of Nopparat Rajathanee Hospital has operated the course, replacing the initial organization by the bureau. The other institute is the Faculty of Medicine, Burapha University, who began teaching the short course in $2012[4,6]$.

\section{Occupational medicine curriculum}

As the first institute to organize the certified occupational medicine residency training program, the Department of Preventive and Social Medicine, Faculty of Medicine, Chulalongkorn University, also serves the graduate master's degree course to fulfill the requirement of the board qualification. The department launched the Master of Science in Occupational Medicine in 1999 [7]. Subsequently, thanks to the challenges in current health care and medical science research issues requiring graduates to apply the field both broadly and deeply, the department launched the Master of Science in Health Research and Management (emphasizing occupational medicine) to replace the Master of Science in Occupational Medicine. The course comprises 24-credit course work and a 12-credit thesis program [8].

\section{Contribution to undergraduate teaching}

The principle of occupational medicine and its relevant skills are widely considered as essential medical student competencies. Basic knowledge of occupational medicine in terms of taking a medical and occupational history and physical examination, health hazard evaluation and control, health promotion and education, and differential diagnosis of occupational diseases is essential for medical students [9]. Moreover, as specified by the Medical Council of Thailand, all physicians practicing in Thailand need to be capable of identifying occupational hazards and risk factors related to health [10]. Thus, there are a number of sessions in the undergraduate curriculum, both in preclinical and clinical years, for Thai medical students, such as the principle of occupational health, occupational diseases and their prevention, workplace hazards, and surveying the workplace.

\section{Serving the nation}

The latest survey shows that there are 159 registered occupational medicine physicians in Thailand comprising 66 of those who accomplished the residency-training category and 93 from the occupational medicine expert scheme in 2016 [11]. Thai occupational medicine physicians are working nationwide in both public and private healthcare facilities. They work in medical schools, general and specialized hospitals, checkup centers, and as physicians in commercial corporations. Interestingly, a number of certified occupational physicians currently occupy various top national health leading positions in Thailand, for instance as members of medical committees and subcommittees of the Workmen Compensation Fund, medical committees and subcommittees of the Social Security Fund, the Health Impact Assessment Commission of the Thai National Health Commission Office, and the board's examining committee for occupational medicine.

\section{Toward the future}

\section{Learning from lessons learned}

Since occupational medicine was established in Thailand, the development of and ideas for occupational medicine have been influenced by the systems in the countries from which pioneering Thai occupational medicine physicians graduated. Thus, learning from developed countries such as the United Kingdom (UK), the United States of America (US), and Singapore has been integral and may suggest directions for occupational medicine training in Thailand in the future.

The UK is a leading country in promoting the well-being of its workforce and occupational health. Contemporary topics for occupational medicine in the UK are chronic diseases and aging populations. The monopoly healthcare provider, the National Health Service, and the industrial sectors still require occupational health services. However, the major issues regarding occupational medicine training in the UK are funding and governance, and the training in occupational medicine needs to be more appealing to potential participants than it has been [12]. 
In the US, socioeconomic factors such as politics and economics always lead and influence occupational medicine. Occupational medicine training in the US is declining because of the lack of applicants and declining labor market demand. By the 1980s, the regulations of Environmental Protection Agency became effective. Many companies in the US have devoted their resources and budgets to environmental issues rather than occupational health and safety. Meanwhile, several enterprises hire part-time noncertified occupational medicine physicians or nurses, instead of occupational medicine physicians. The current working conditions and formats are also shifting from the industrializing period to the service and other sectors. Occupational medicine training programs are suffering from insufficient funding support. Occupational medicine is not popular among newly graduated physicians in the US. Some experts suggest that the situation of occupational medicine training could be improved by adding broader content and enhancing the protection of the international workforces of global corporations [13].

Singapore, led by the National University of Singapore, has founded certified postgraduate occupational medicine training in the Master of Medicine in Occupational Medicine and Public Health graduate diploma course in occupational medicine program since 1992. Experience from the training in Singapore suggests that critical thinking skills suitable for occupational medicine and other public health-related training are necessary in both undergraduate and postgraduate instructions. In addition, multidisciplinary application including basic medical and clinical sciences is essential to develop occupational medicine training [14].

Thailand, as a country whose occupational medicine training program is still being developed from its initial stages, requires updated content and employer demand for success. Furthermore, occupational medicine training and qualifying management including curriculum, instruction, and assessment procedures need to be standardized and accepted and recognized internationally [15]. The Association of Occupational and Environmental Diseases of Thailand is the main authority dealing with these challenges.

\section{Challenging issues in occupational medicine training}

There are future challenges. The supply of occupational medicine physicians remains inadequate. A majority of Thai working populations are in the informal sector, particularly in agriculture, and this should be considered in the training. Additionally, the advancement of current health research schemes including large data analysis and basic science integration should be harnessed to influence the progression of occupational medicine training in Thailand.

\section{Supply of occupational physicians}

Occupational diseases and injuries consume a significant portion of the national budget in Thailand. According to the Workmen's Compensation Act issued in 1994, the Thai Workmen Compensation Fund is responsible for compensation to workers associated with occupational injuries and illnesses. The compensation fund also covers those disabled or killed by work-related accidents and illnesses. Occupational physicians are expected to play a role in assessing workrelated conditions related to compensation decisions [16]. Thereby, occupational medicine physicians have a responsible role. An important duty of occupational medicine training stakeholders is to serve this demanding task.

\section{Informal sector occupational study: agricultural workers}

Statistically, $62.6 \%$ of the working population in Thailand is in the informal sector workforce. The informal sector workers significantly contribute towards Thailand's economy. However, the Labor Protection Act does not protect informal workers. The Thai Social Security Scheme has not defined coverage for informal workers. Interestingly, the rate of occupational illnesses and injuries in the informal sector is significantly high [17]. Specifically, a number of previous studies of agricultural workers in Thailand (approximately 16.7 million), the largest proportion of the workforce in Thailand, suggest that agriculturalists or agrarian workers in Thailand suffer from various occupational hazards related to excessive use of hazardous chemicals and ergonomic problems. In addition, agriculturalists in Thailand often lack appropriate health education and knowledge for self-protection from hazardous working conditions and workplaces. Yet, there is little published knowledge regarding health of agrarians in Thailand [18]. Thus, occupational medicine training with a focus on informal sectors, particularly agriculture, would make a significant contribution to the health of the population in Thailand.

\section{Bridging the gap with biomedical sciences and large data analysis}

Occupational medicine training in Thailand should be developed together with scientific research to benefit occupational health services at the societal level. To usher the field of occupational medicine into a new era of training, bridging the gap between spheres of epidemiology, public 
health, and clinical and biomedical sciences is crucial [14]. The next generation of occupational medicine trainees should be competent in multidisciplinary knowledge. In the UK, there are groups of occupational medicine researchers who have studied the associations between occupational factors and clinical features in working populations by using basic medical sciences and large data analysis. Systematic data collection of occupational category is useful for these types of studies [19]. All things considered, this could form a prospective model for future occupational medicine study and training in Thailand.

\section{Conclusion}

Since 1998, the occupational medicine training program initially organized by the Department of Preventive and Social Medicine, Faculty of Medicine, Chulalongkorn University, has contributed graduates who significantly serve health care and well-being of the working population nationwide both in public and private sectors. However, compared with other clinical specialties, occupational medicine training in Thailand is still in its initial stages. The progression of occupational medicine training relies on several factors. To maintain the sustainability of occupational medicine training, pursuing challenging global occupational medicine issues, principally regarding advanced scientific research application to Thai occupational health circumstances with the training, is considered essential.

Author contributions. JR and PS substantially contributed to the conception and design, research analysis, and interpretation of data of the article. Both authors drafted and critically revised the manuscript, approved the final version submitted for publication, and take responsibility for the statements made in the article.

Acknowledgments. This research did not receive any specific grant from funding agencies in the public, commercial, or not-for-profit sectors. Jate Ratanachina is currently a visiting scholar in the Department of Occupational and Environmental Medicine, National Heart and Lung Institute, Imperial College London, London SW3 6LR, UK, but retains King Chulalongkorn Memorial Hospital, Bangkok, as a permanent address.

Conflict of interest statement. The authors declare no conflict of interest with respect to publication of this article.

\section{References}

[1] Sithisarankul P. Occupational versus environmental medicine: similarities and differences. Intern Med J Thai. 2003; 19:293.

[2] National Statistical Office of Thailand. Working population in January 2017 survey: National Statistical Office of Thailand. [online] 2017 [cited 2017 Feb 21]. Available at http://service.nso.go.th/nso/ nsopublish/themes/files/lfs60/reportJan.pdf. [in Thai]

[3] Bundhukul A. Career progress for occupational medicine physicians. In: Bundhukul A, editor. Textbook of occupational medicine. Bangkok: Ratchathun Press; 2011. p. 38-72.

[4] Sithisarankul P. Training in occupational medicine in Thailand. Intern Med J Thai. 2003; 19:86-7.

[5] Department of Preventive and Social Medicine. Graduate diploma of clinical sciences program in occupational medicine curriculum (BE 2547). Bangkok: Chulalongkorn University; 2004. [in Thai].

[6] Daengsawat P, Ekburanawat W, Janthayanont D, Chantawong C. A survey of occupational health and safety professionals in Thailand in 2014. Thammasat Med J. 2015; 15:393-405. [in Thai, English abstract].

[7] Department of Preventive and Social Medicine. Master of Science in Occupational Medicine Curriculum (BE 2542). Bangkok: Chulalongkorn University; 1999. [in Thai].

[8] Department of Preventive and Social Medicine. Master of Science in Health Research and Management Curriculum (BE 2556). Bangkok: Chulalongkorn University; 2013. [in Thai].

[9] Buranatrevedh S. A need assessment study of occupational health curriculum for Thai medical students. J Med Assoc Thai. 2007; 90:1894-907.

[10] Medical Competency Assessment Criteria for National License BE 2555 (2012). [online] 2012 [cited 2017 March 07]. Available at: https://www.tmc.or.th/file_08062012.pdf. [in Thai and English].

[11] The Medical Council of Thailand. Board-certified Physicians from the Medical Council of Thailand Statistics: The Medical Council of Thailand. [online] 2016. [cited $2017 \mathrm{Feb} 23$ ]. Available at: http:// www.tmc.or.th/pdf/4total_authorization2507-2559.pdf. [in Thai].

[12] Harrison J. A future forum for UK occupational health? Occup Med (Lond). 2012; 62:590-1.

[13] Gochfeld M. Occupational medicine practice in the United States since the industrial revolution. J Occup Environ Med. 2005; 47:115-31.

[14] Wong ML, Koh D, Phua KH, Lee HP. Teaching community, occupational and family medicine at the National University of Singapore: past, present and future. Ann Acad Med Singapore. 2005; 34:102C-7C.

[15] Schneider JD, Aw TC. Occupational health practice: training and accreditation. Indian J Occup Environ Med. 2012; 16:45-6.

[16] Thepaksorn P, Pongpanich S. Occupational injuries and illnesses and associated costs in Thailand. Saf Health Work. 2014; 5:66-72.

[17] Kongtip P, Nankongnab N, Chaikittiporn C, Laohaudomchok W, Woskie S, Slatin C. Informal workers in Thailand: occupational health and social security disparities. New Solut. 2015; 25:189-211.

[18] Kaewboonchoo O, Kongtip P, Woskie S. Occupational health and safety for agricultural workers in Thailand: gaps and recommendations, with a focus on pesticide use. New Solut. 2015; 25:102-20.

[19] De Matteis S, Jarvis D, Hutchings S, Darnton A, Fishwick D, Sadhra S, et al. Occupations associated with COPD risk in the large populationbased UK Biobank cohort study. Occup Environ Med. 2016; 73:378-84. 
